\title{
Blood Glucagon Levels Predict the Hemoglobin A1c Response to Saxagliptin in Patients with Type 2 Diabetes Inadequately Controlled with Metformin
}

\author{
Hao Liu $\cdot$ Yun Hu · Feng-fei Li · Bing-li Liu · Xiao-fei Su • \\ Jian-hua Ma
}

Received: August 16, 2016 / Published online: October 12, 2016

(C) The Author(s) 2016. This article is published with open access at Springerlink.com

\begin{abstract}
Background: Dipeptidyl peptidase-4 (DPP-4) inhibitors are widely used as second-option medications when metformin fails. Variance of the glycated hemoglobin (HbA1c) response to DPP-4 inhibitions in patients with type 2 diabetes mellitus (T2DM) has been observed, but the characteristics which predict the response to DPP-4 inhibitor therapy are unclear. The aim of this study was to investigate the characteristics of $\alpha$ - and $\beta$-cell functions which might predict the efficacy of saxagliptin and facilitate personalization of treatment.
\end{abstract}

Methods: We studied 60 patients with T2DM who had inadequate glycemic control [HbA1c7.0-13.0\% (53-119 mmol/mol)) with

Hao Liu and Yun Hu contributed equally to this paper.

Enhanced content To view enhanced content for this article go to http://www.medengine.com/Redeem/ 12E6F06005FA780C.

H. Liu · Y. Hu · F. Li · B. Liu · X. Su (ه) · J. Ma (ه)

Department of Endocrinology, Nanjing First

Hospital, Nanjing Medical University, Nanjing,

China

e-mail: suxiaofeifei@126.com

J. Ma

e-mail: majianhua196503@126.com metformin alone. The patients were treated with saxagliptin (5 mg, daily) and metformin (1000-2000 mg as former) for 12 weeks. Oral glucose tolerance tests were carried out at baseline and endpoint to evaluate $\alpha$ - and $\beta$-cell functions, and blood C-peptide, insulin, glucagon levels were tested. Blood glucose, HbA1c and weight were also observed.

Results: Significant reduction of weight, HbA1c and glucagon was observed after 12-week treatment, while C-peptide, insulin and homeostasis model assessment- $\beta$ increased $(P<0.05)$. Linear regression and receiver operating characteristic analysis showed that baseline HbA1c and 30 min-glucagon were correlated with the HbA1c response to saxagliptin, while the weight loss was correlated with gender, age and fasting-insulin level. Further analysis showed the 30 min-glucagon of $49.1 \mathrm{pmol} / \mathrm{L}$ was the optimal cutoff value to predict the efficacy of saxagliptin.

Conclusions: Saxagliptin added to metformin significantly improved glycemic control and $\alpha$ and $\beta$-cell function. Blood glucagon level was a good predicting factor for the HbA1c response to saxagliptin, and it will help appropriate patient selection. 
Trial registration: Chinese Clinical Trial Register identifier, ChiCTR-PPR-15007045.

Keywords: Efficacy; Glucagon; Saxagliptin; T2DM

\section{INTRODUCTION}

Dipeptidyl peptidase-4 (DPP-4) inhibitors are a kind of oral anti-diabetic agents that increase circulating concentrations of the glucagon-like peptide-1 (GLP-1) in non-insulin-dependent diabetes mellitus (T2DM) [1]. DPP-4 inhibitors may improve $\beta$-cell function in patients with T2DM [2] and inhibit $\alpha$-cell function [3]. In the 2012 position statement of the American Diabetes Association and European Association for the Study of Diabetes, DPP-4 inhibitors were considered as second-option medication when metformin fails.

Along with wide use of DPP-4 inhibitions, variance of the glycated hemoglobin (HbA1c) response to DPP-4 inhibitions in patients with T2DM has been observed. As a result, the characteristics of phenotypic, genotypic or biochemical for predicting the response to DPP-4 inhibitors were badly required. A meta-regression analysis involving 79 arms and 2,0503 patients showed that baseline HbA1c and fasting glucose contributed to the reduction of HbA1c [4]. Previous studies also found that about $30 \%$ of patients with T2DM had resistance to GLP-1 which may be caused by gene variants, such as GLP1R, transcription factor 7-like 2 (TCF7L2) and wolframin ER transmembrane glycoprotein (WSF-1) gene variation [5-7]. All of these genes affect $\beta$-cell functions, including insulin production and secretion and $\beta$-cell proliferation [8-10]; GLP1R and TCF7L2 were also identified in $\alpha$-cells and were found to affect glucagon secretion $[11,12]$. Therefore, we inferred that $\alpha$ - and $\beta$-cell functions, influenced by both genetic factors, and acquired disposition like blood glucose and duration of diabetes, may predict the efficacy of DPP-4 inhibitors. However, the influence of baseline $\alpha$ - and $\beta$-cell function on the efficacy of DPP-4 inhibitors in patients with T2DM has not been observed.

Saxagliptin is demonstrated to be effective and safe comparing with placebo in Asian patients with T2DM who had inadequate glycemic control with or without metformin and diet and lifestyle modification [13, 14]. There was no difference in fasting insulin or glucagon between saxagliptin group and the placebo group in previous study, but postprandial C-peptide and $\beta$-cell function based on the homeostasis model assessment (HOMA)- $\beta$ were improved by saxagliptin treatment [14]. Another study in patients with T2DM poorly controlled with metformin monotherapy showed that saxagliptin suppressed glucagon response significantly [15]. However, the relationship between postprandial glucagon and efficacy of saxagliptin was unobserved. In the present study, oral glucose tolerance tests (OGTTs) were used for evaluating $\alpha$ - and $\beta$-cell functions in patients with T2DM inadequately controlled with metformin treated with saxagliptin as add-on therapy, thereby trying to find predictive factors on the efficacy of saxagliptin.

\section{METHODS}

\section{Patients}

The patients with T2DM who had inadequate glycemic control with metformin were 
consecutively recruited from the Nanjing First Hospital between June 2013 and June 2015. Patients with HbA1c of $7.0-13.0 \%$ (53-119 $\mathrm{mmol} / \mathrm{mol})$ and body mass index (BMI) $>24 \mathrm{~kg} / \mathrm{m}^{2}$ were required to have been treated with metformin (1000-2000 mg, daily) for at least 12 weeks and to be on a stable dose. Major exclusion criteria were patients with a history of insulin-dependent diabetes mellitus or diabetes due to pancreatic injury or secondary forms of diabetes, any acute metabolic diabetic complications such as ketoacidosis or hyperosmolar state (coma) within past 6 months, patients using insulin or other oral hypoglycemic agents (sulfonylureas, acarbose, DPP-4 inhibitors or thiazolidinediones), pregnant, alanine aminotransferase (ALT) levels more than two times the upper normal range, noncompliance because of psychiatric or other serious diseases, or unwillingness to participate in the study. Each participant provided a signed informed consent to participate in the study. The study was approved by the ethics committee of Nanjing First Hospital.

\section{Study Design}

Eligible patients were treated with saxagliptin (5 mg, daily), and metformin (former dosage was maintained) for 12 weeks, and underwent OGTTs using $75 \mathrm{~g}$ of glucose (dissolved in $200 \mathrm{ml}$ water) before and after the 12-week saxagliptin treatment. Serum samples were obtained before and 30 and $120 \mathrm{~min}$ after oral administration for blood glucose, insulin, C-peptide and glucagon determination. The ratios of glucagon/glucose (GLA/GLU) and glucagon/insulin (GLA/INS) were calculated to represent the inhibition of glucose or insulin on glucagon secretion [16]. Assessments also included BMI, HbA1c, and routine urine analysis (for urine protein and urinary ketone measurement) at baseline and the endpoint of 12 weeks. Dietary and lifestyle modifications were reinforced during the treatment period. Blood glucose was monitored every week, while ALT and creatinine were tested every 4 weeks.

\section{Laboratory Methods}

Plasma glucose was measured using the glucose oxidase method. Insulin and C-peptide were measured by chemiluminescent immunometric assay on the Modular Analytics E170 analyzer (Roche $^{\circledR}$ Diagnostics GmbH, Mannheim, Germany). Glucagon was determined with a quantitative radioimmunoprecipitation assay kit (Beijing North Institute of Biological Technology, China), and the intra- and inter-assay coefficients of variation were 6.6 and $12.0 \%$, respectively. HbA1c was measured by high-performance liquid chromatography assay (Bio-Rad Laboratories, Inc. CA, USA).

\section{Statistics}

Analyses were performed using the SPSS Version 16.0 (SPSS Inc, Chicago, IL, USA) statistical package. All variables were tested for normal distribution of the data. Data are presented as mean \pm standard error. Predictive factors were found with stepwise multivariate linear regression analysis. The cutoff value of glucagon and HbA1c was calculated by receiver operating characteristic (ROC) analysis. Efficacy of saxagliptin was analyzed by paired $t$ test, while differences between the groups were examined using Student's unpaired $t$ test. All comparisons were two-sided at 5\% significance level. $P$ value $<0.05$ was considered to be statistically significant. 


\section{RESULTS}

\section{Patients and Saxagliptin Efficacy}

Among the 64 enrolled patients, 60 patients (including 29 male and 31 female, aged 29-70 years) completed the treatment. Three patients were excluded because of intolerable hyperglycemia (fasting plasma glucose was $>13.3 \mathrm{mmol} / \mathrm{L}$ at week 4 or 8 ), while one patient was withdrawn due to increased ALT. The mean duration of T2DM was 2.8 years. The baseline BMI was $28.63 \pm 0.32 \mathrm{~kg} / \mathrm{m}^{2}$ and HbA1c was $9.2 \pm 0.2 \% \quad(77 \pm 2 \mathrm{mmol} / \mathrm{mol})$. Significant reduction of weight, HbA1c, glucagon and the ratio of GLA/INS and fasting GLA/GLU was observed after 12-week treatment, while C-peptide as well as insulin increased. Area under the insulin curve (AUC(INS)) and HOMA- $\beta$ were calculated to reflect the change of $\beta$-cell function. After 12-week saxagliptin treatment combined with metformin, HOMA- $\beta$ increased significantly (Fig. 1).

\section{Regression Analysis}

The decline of HbA1c $(\Delta \mathrm{HbA} 1 \mathrm{c})$ and weight loss ( $\Delta$ weight) was calculated. The relationships between efficacy of saxagliptin (indicated by $\Delta \mathrm{HbA} 1 \mathrm{c}$ and $\Delta$ weight) and baseline blood glucose, insulin, glucagon, GLA/INS, BMI and base characteristics, such as gender, age, duration of T2DM, were analyzed by linear regression with a stepwise procedure. In the multivariate linear regression analysis, the association between $\triangle \mathrm{HbA} 1 \mathrm{c}$ and baseline HbA1c, and 30 min-glucagon reached statistical significance, whereas the significantly correlative factors of $\Delta$ weight were the age and 120 min-GLA/INS (Table 1 ).

\section{The ROC Curve for Predicting HbA1c} Response to Saxagliptin

According to the results of linear regression analysis, 30 min-glucagon was a predictive factor of $\mathrm{HbA1c}$ response to saxagliptin as well as baseline HbA1c. ROC analysis was drawn to calculate the optimal cutoff value for 30 min-glucagon and HbA1c (Fig. 2). The $\Delta \mathrm{HbA} 1 \mathrm{c}<1.0 \% \quad(11 \mathrm{mmol} / \mathrm{mol}) \quad$ [included 10 patients with $\triangle \mathrm{HbA} 1 \mathrm{c}$ from 0 to $0.2 \%$ $(0-2 \mathrm{mmol} / \mathrm{mol})]$ was considered as non-response to saxagliptin, while $\Delta \mathrm{HbA} 1 \mathrm{c}>1.0 \% \quad(11 \mathrm{mmol} / \mathrm{mol}) \quad$ [included 21 patients with $\triangle \mathrm{HbA1c}$ from 1.2 to $4.5 \%$ (13-26 mmol/mol)] was considered as optimal efficacy of saxagliptin. The cutoff value, sensitivity, specificity and area under ROC (AUC) of 30 min-glucagon and baseline HbA1c are shown in Table 2.

\section{Saxagliptin Efficacy Comparison}

The patients were divided into high/ low-glucagon and high/low HbA1c groups according to the results of ROC analysis. There was no difference in baseline HbA1c, weight, BMI and HOMA- $\beta$ between low-glucagon ( $n=23$, baseline 30 min-glucagon $<49.1 \mathrm{pmol} /$ L) and high-glucagon $(n=37$, baseline 30 min-glucagon $\geq 49.1 \mathrm{pmol} / \mathrm{L}$ ) groups. However, the changes in HbA1c, weight, BMI and HOMA- $\beta$ after 12-weeks of saxagliptin treatment were significantly greater in the high-glucagon group than in the low-glucagon group (Fig. 3a). The HbA1c levels at baseline and endpoint were lower in low-HbA1c group ( $n=23$, baseline HbA1c $<8.7 \%$ [72 $\mathrm{mmol} / \mathrm{mol}]$ ) than in high-HbA1c group $[n=37$, baseline HbA1c $\geq 8.7 \% \quad(72 \mathrm{mmol} / \mathrm{mol})]$; however, no difference was observed in weight, BMI or HOMA- $\beta$ between the two groups (Fig. 3b). 

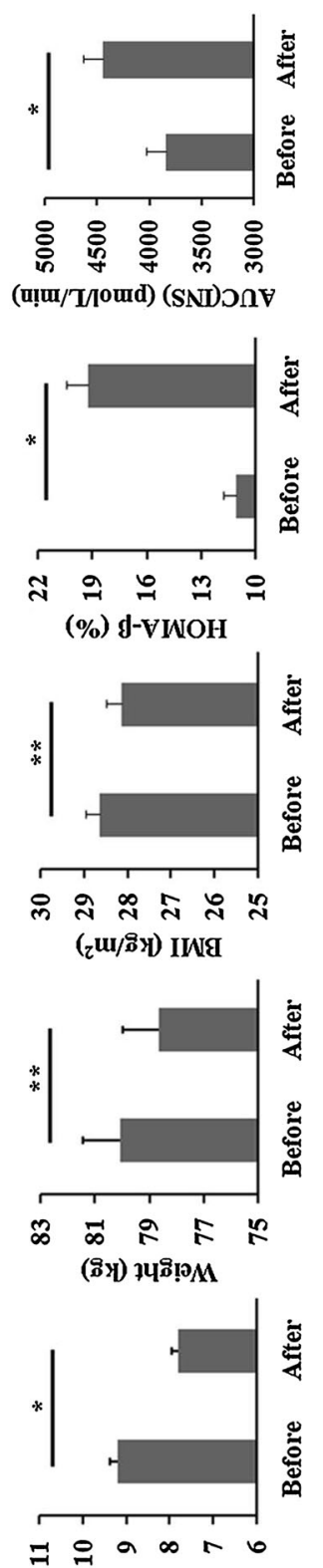

(ర) (\%) गIVqH

品

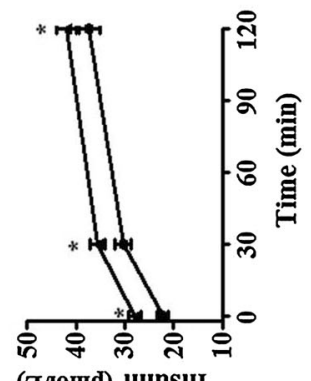

(T/10md) u!̣nsuI
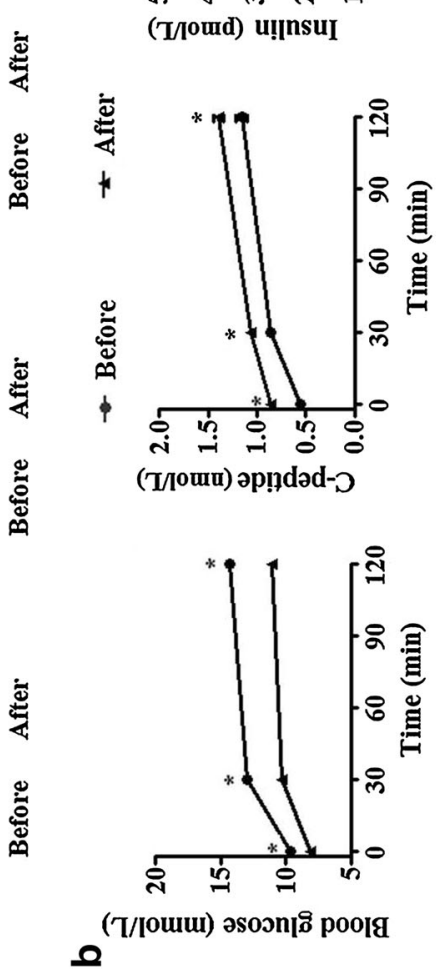
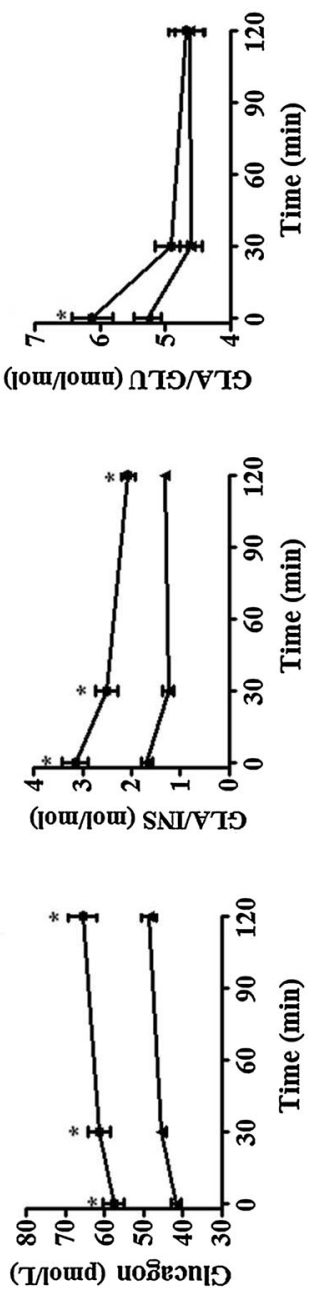

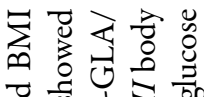

च्ञ

त苞出

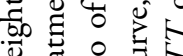

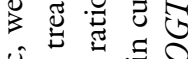

过寻艺泀

可矛矛

औ

定

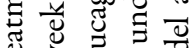

5 का एँ

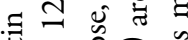

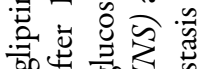

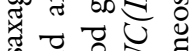

ये च유

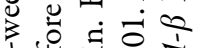

ปับ

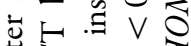

㼛式式

$\sim 0$ तै

ค

थे

है के वे

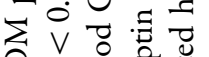

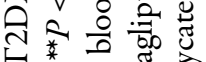

I*

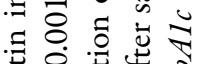

원류

to

药

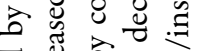

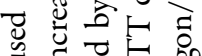

ปั

घ

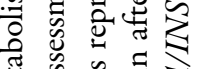

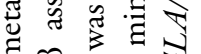

文氜心

ơ⿺

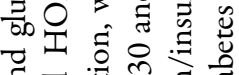

สี

대 है है

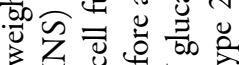

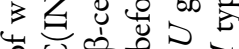

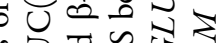

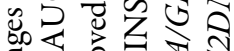

जै जी

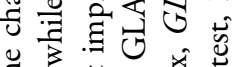

릴

- 氖氜

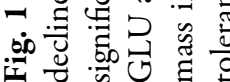


Table 1 Linear regression analysis for predictive factors of saxagliptin efficacy in patients with T2DM

\begin{tabular}{lcc}
\hline & Standardized $\boldsymbol{\beta}$ & $\boldsymbol{P}$ value \\
\hline Correlate with $\Delta$ HbA1c & & \\
HbAlc & 0.487 & $<0.001$ \\
30 min-glucagon & 0.536 & $<0.001$ \\
Correlate with $\Delta$ weight & & \\
Age & -0.262 & 0.029 \\
Fast-insulin & 0.384 & 0.002 \\
\hline
\end{tabular}

Covariates age, gender, duration of T2DM, height, baseline $\mathrm{HbAlc}$, weight and BMI, baseline blood glucose, insulin, C-peptide, glucagon and GLA/INS before and $30 \mathrm{~min}$, and $2 \mathrm{~h}$ after OGTT, and baseline AUC(INS)

$\triangle H b A 1 c$ baseline HbAlc-endpoint HbAlc, $\Delta$ weight baseline weight-endpoint weight, $A U C(I N S)$ area under the insulin curve, $B M I$ body mass Index, GLA/INS glucagon/insulin, HbAIc glycated hemoglobin, $O G T T$ oral glucose tolerance test, T2DM type 2 diabetes mellitus

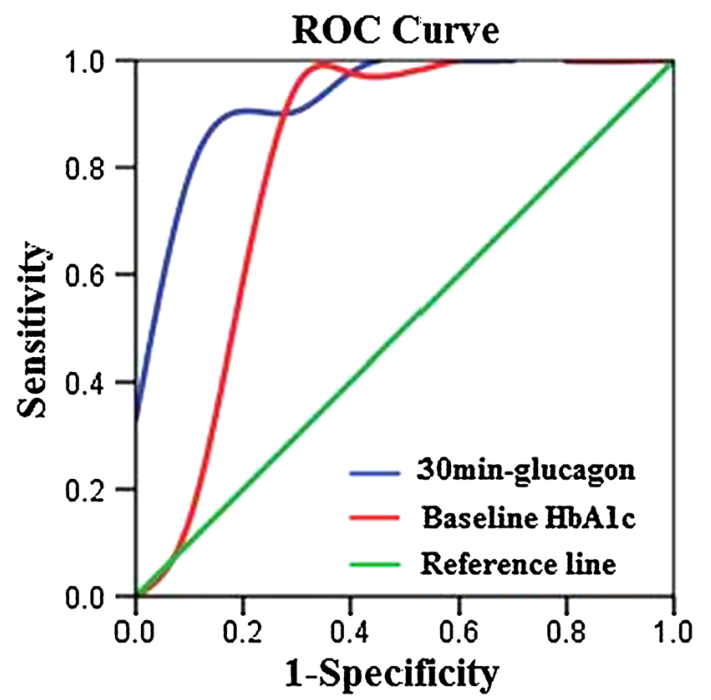

Fig. 2 The ROC curve of HbAlc declines with glucagon and baseline HbA1c in T2DM patients. The cutoff value of 30 min-glucagon and baseline HbAlc was calculated by ROC analysis. The $\triangle \mathrm{HbAlc}<1.0 \%$ was considered as non-response to saxagliptin, while $\Delta \mathrm{HbA} 1 \mathrm{c}>1.0 \%$ was considered as optimal efficacy of saxagliptin. HbAlc glycated hemoglobin, ROC receiver operating characteristic, T2DM type 2 diabetes mellitus

\section{DISCUSSION}

The prevalence of T2DM increased rapidly in recent years, and the number of patients with T2DM is expected to rise to 552 million by 2030 [17]. Due to the large amount of patients and the availability of at least 10 drug classes for the treatment of T2DM, the ideal drug sequence after metformin failure is an area of increasing uncertainty [18]. Thus, precision medicine, taking account of human individuality in genes, environment, and lifestyle for early disease diagnosis, and individualized therapy, have been required in the treatment of T2DM at this time.

DPP-4 inhibitors, including saxagliptin, are accepted by more and more patients due to their effectiveness in glycemic control and less side-effect in hypoglycemia and weight gain [19]. Our study confirms that saxagliptin in combination with metformin is effective in improving glycemic control and losing weight. The effects of restoring $\alpha$ - and $\beta$-cell functions in patients with T2DM were also observed, which were consistent with previous studies [20, 21].

The decline of $\mathrm{HbA} 1 \mathrm{c}$ was $1.4 \pm 0.1 \%$ $(15 \pm 1 \mathrm{mmol} / \mathrm{mol})$ in our study, which was higher than previous studies $[\Delta \mathrm{HbA} 1 \mathrm{c}$ ranged from $-0.9 \% \quad(-10 \mathrm{mmol} / \mathrm{mol})$ to $-0.5 \%$ ( $-5 \mathrm{mmol} / \mathrm{mol})$ ] [22-24]. The reason may be the high baseline HbA1c of our patients which is indicating increased $\Delta \mathrm{HbA} 1 \mathrm{c}$, and the evidence was demonstrated both in the present and previous studies [4].

In our study, blood glucagon level, especially the 30 min-glucagon in OGTT, was significantly associated with $\mathrm{HbA1c}$ response to saxagliptin according to the linear regression and ROC analysis, which may be considered as a good predictive factor of saxagliptin efficacy. However, $\beta$-cell function, such as insulin, C-peptide and AUC (INS), had been slightly 
Table 2 Optimal cutoff value of 30 min-glucagon and baseline HbAlc calculated with ROC analysis for predicting HbAlc response to saxagliptin in patients with T2DM

\begin{tabular}{llllllr}
\hline & Cutoff value & Sensitivity (\%) & Specificity (\%) & AUC & 95\% CI & $P$ value \\
\hline 30 min-glucagon & $49.1 \mathrm{pmol} / \mathrm{L}$ & 90.5 & 90.0 & 0.940 & $0.859-1.022$ & $<0.001$ \\
Baseline HbAlc & $8.65 \%(72 \mathrm{mmol} / \mathrm{mol})$ & 90.5 & 80.0 & 0.819 & $0.605-1.033$ & 0.005 \\
\hline
\end{tabular}

$A U C$ area under ROC curve, $C I$ confidence interval, $H b A l c$ glycated hemoglobin, $R O C$ receiver operating characteristic, $T 2 D M$ type 2 diabetes mellitus

relevant to saxagliptin efficacy. The results indicated that saxagliptin improved glycemic control by modulating $\alpha$-cell function rather than $\beta$-cell function.

Glucagon accounts for $40-50 \%$ of basal hepatic glucose production [25] and plays a role in postprandial glucose homeostasis [26], as it is under paracrine control by insulin. Our study showed that GLA/INS was decreased by saxagliptin in patients with T2DM, indicating an improved inhibition of insulin on glucagon. Saxagliptin also improved the inhibition of glucose on glucagon in the fasting state.

The mechanism of glucagon level decreased by GLP-1 remains unclear. Gromada et al. found that GLP-1 has minimal activity with glucagon receptor [27]. However, most studies have not localized the GLP-1 receptor to $\alpha$-cells [28]. Blood glucagon level may correlate with the capacity of GLP-1 production in vivo, because GLP-1 is a product of proglucagon that has nearly 50\% homology to glucagon [29]. Recently, Kushiyama et al. found that blood glucagon level had no correlation with active GLP-1 level, though active GLP-1 level in plasma was associated with the efficacy of DPP-4 inhibitors in patients with T2DM [30]. However, GLP-1 has a short half-life (less than $2 \mathrm{~min}$ ) due to rapid degradation by the enzyme DPP-4, and is difficult to be detected routinely; by contrast, glucagon is stable and detectable as a predictor used in clinical medicine.
According to our study, blood glucagon level was more outstanding than baseline HbA1c, which was the predictor recommended in previous studies [4, 31]. There were more significant improvements not only in HbA1c but also in weight and $\beta$-cell function in high-glucagon group than in low-glucagon group, while baseline HbA1c could only predict the HbA1c response to saxagliptin combined with metformin.

Blood glucagon levels may also be related to efficacy of other drugs which affect glucagon secretion, such as insulin and sodium-glucose cotransporter-2 (SGLT2) inhibitors. SGLT2 inhibitors have an opposite effect on glucagon compared with DPP-4 inhibitors [32, 33], and the relationship between blood glucagon levels and the drug efficacy needs further investigation.

Considering the effects of metformin and saxagliptin on losing weight, we chose overweight patients with $\mathrm{BMI}>24 \mathrm{~kg} / \mathrm{m}^{2}$. Previous study showed that the suppression of glucagon secretion during hyperglycemia was impaired in obese mice [34]. Fasting hyperglucagonemia was observed in obese people who, despite their insulin-resistant state, have normal glucose tolerance and may constitute very early steps in the pathophysiology of T2DM as well as a reduced incretin effect [35]. Therefore, our study showed significant higher blood glucagon level compared with previous study 


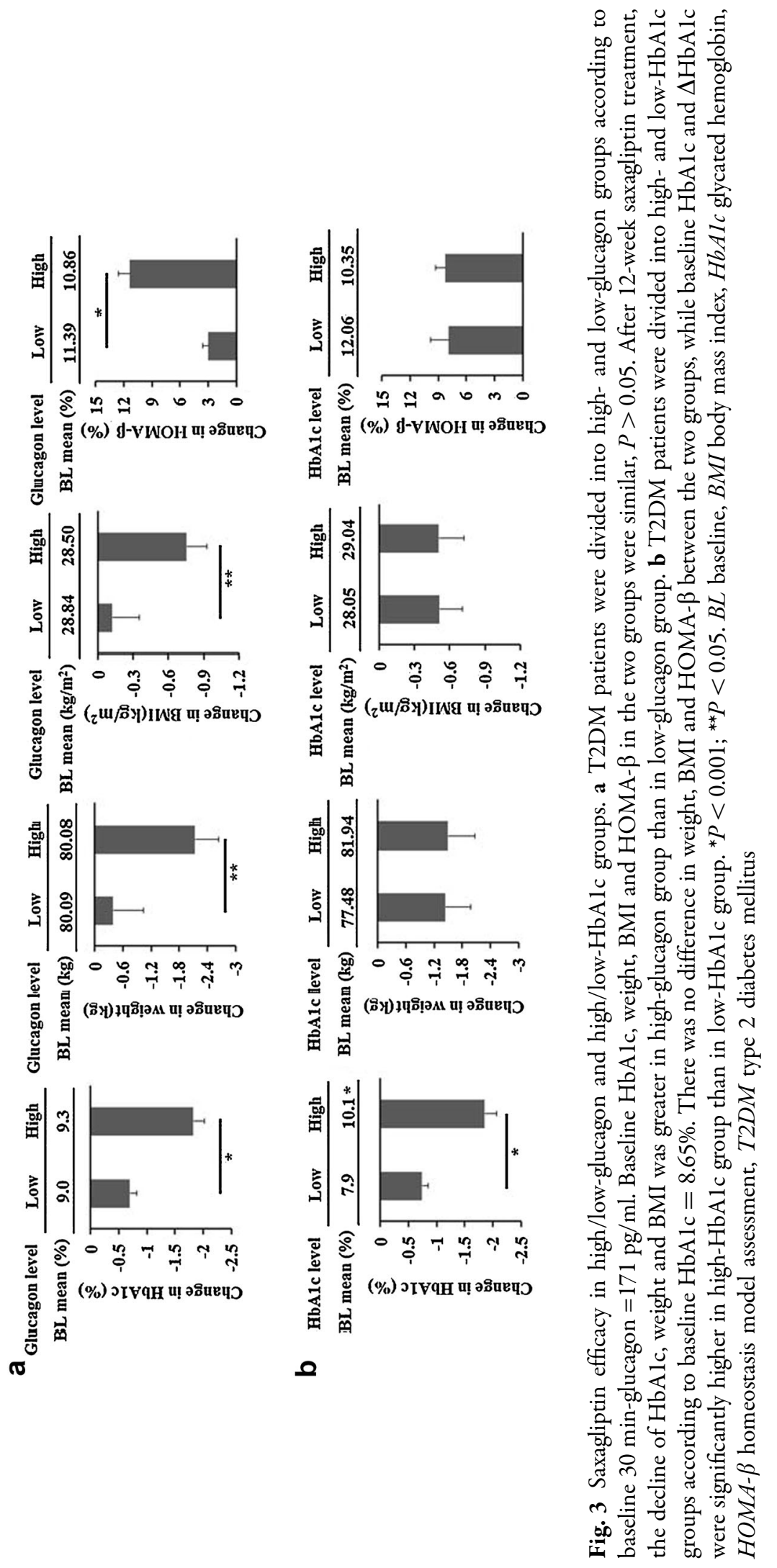


(baseline mean glucagon: 57.6 vs. 19.0 pmol/L) [14]. This may also explain the significant decrease of HbA1c after saxagliptin treatment.

There was no significant weight loss after saxagliptin treatment in Chinese patients in previous studies $[13,14]$. However, in our study, weight and BMI decreased after saxagliptin treatment. Younger and high $120 \mathrm{~min}-\mathrm{GLA} /$ INS may be correlated with increased weight loss. The patients recruited in our study had lower insulin and C-peptide levels than in previous studies [14, 19], which may have been caused by a higher glucotoxicity.

Limitations of this study include the lack of a placebo control which precludes effects of metformin, dietary and lifestyle modifications. In the previous study with a duration of 24 weeks, the decline of $\mathrm{HbA} 1 \mathrm{c}$ was only $0.4 \%$ $(4 \mathrm{mmol} / \mathrm{mol})$ in metformin + placebo group with reinforced diet and lifestyle [14], while other studies showed that metformin had no effect on glucagon suppression [15, 36]. However, the effects of metformin, dietary and lifestyle modifications may not be ignored. Moreover, possible long-term efficacy and the durability of saxagliptin may be unobserved according to the 12-week duration of study. More patients with variance of weight, duration of diabetes, glucose control and $\beta$-cell function, and classes of DPP-4 inhibitors should be included in our study to determine the cutoff value of glucagon.

\section{CONCLUSION}

Saxagliptin combined with reinforced diet and lifestyle improved glycemic control by modulating $\alpha$ - and $\beta$-cell functions in patients with T2DM inadequately controlled with metformin. However, the high non-responder rate to DPP-4 inhibitors should not be ignored. Blood glucagon levels are effective for predicting efficacy of saxagliptin combined with metformin. This finding may help doctor prescription and reduce the cost of invalid drug use for patients with T2DM.

\section{ACKNOWLEDGMENTS}

This research was funded by Jiangsu Provincial Department of Science and Technology Project (No. BL2014010) and National Natural Science Foundation of China (No. 81400780).

All named authors meet the International Committee of Medical Journal Editors (ICMJE) criteria for authorship for this manuscript, take responsibility for the integrity of the work as a whole, and have given final approval for the version to be published.

Disclosures. H Liu, Y. Hu, F-F Li, B-Li Liu, $\mathrm{X}-\mathrm{F} \mathrm{Su}$ and J-H Ma have nothing to disclose.

Compliance with Ethics Guidelines. The study was approved by the ethics committee of Nanjing First Hospital. Informed consent was obtained from all patients for being included in the study.

Open Access. This article is distributed under the terms of the Creative Commons Attribution-NonCommercial 4.0 International License (http://creativecommons.org/licenses/ by-nc/4.0/), which permits any noncommercial use, distribution, and reproduction in any medium, provided you give appropriate credit to the original author(s) and the source, provide a link to the Creative Commons license, and indicate if changes were made. 


\section{REFERENCES}

1. Inzucchi SE, McGuire DK. New drugs for the treatment of diabetes: part II: incretin-based therapy and beyond. Circulation. 2008;117(4):574-84. doi:10.1161/

CIRCULATIONAHA.107.735795.

2. Nauck MA. Incretin-based therapies for type 2 diabetes mellitus: properties, functions, and clinical implications. Am J Med. 2011;124(1 Suppl):S3-18. doi:10.1016/j.amjmed.2010.11.002.

3. Panina G. The DPP-4 inhibitor vildagliptin: robust glycaemic control in type 2 diabetes and beyond. Diabetes Obes Metab. 2007;9(Suppl 1):32-9.

4. Esposito K, Chiodini P, Capuano A, Maiorino MI, Bellastella G, Giugliano D. Baseline glycemic parameters predict the hemoglobin A1c response to DPP-4 inhibitors. Endocrine. 2014;46(2):43-51. doi:10.1007/s12020-013-9918-x.

5. Herzberg-Schäfer S, Heni M, Stefan N, Häring HU, Fritsche A. Impairment of GLP1-induced insulin secretion: role of genetic background, insulin resistance and hyperglycaemia. Diabetes Obes Metab. 2012;14(Suppl 3):85-90. doi:10.1111/j. 1463-1326.2012.01648.x.

6. de Luis DA, Aller R, Izaola O, de la Fuente B, Primo $\mathrm{D}$, Conde R, et al. Evaluation of weight loss and metabolic changes in diabetic patients treated with liraglutide, effect of RS 6923761 gene variant of glucagon-like peptide 1 receptor. Ann Nutr Metab. 2013;63(4):277-82. doi:10.1159/000356710.

7. Jamaluddin JL, Huri HZ, Vethakkan SR, Mustafa N. Pancreatic gene variants potentially associated with dipeptidyl peptidase- 4 inhibitor treatment response in Type 2 diabetes. Pharmacogenomics. 2014;15(2):235-49. doi:10.2217/pgs.13.234.

8. Villareal DT, Robertson H, Bell GI, Patterson BW, Tran H, Wice B, et al. TCF7L2 variant rs7903146 affects the risk of type 2 diabetes by modulating incretin action. Diabetes. 2010;59(2):479-85. doi:10.2337/db09-1169.

9. Ishihara $\mathrm{H}$, Takeda $\mathrm{S}$, Tamura A, Takahashi $\mathrm{R}$, Yamaguchi S, Takei D, et al. Disruption of the WFS1 gene in mice causes progressive beta-cell loss and impaired stimulus-secretion coupling in insulin secretion. Hum Mol Genet. 2004;13(11):1159-70. doi:10.1093/hmg/ddh125.

10. Sathananthan A, Man CD, Micheletto F, Zinsmeister AR, Camilleri M, Giesler PD, et al. Common genetic variation in GLP1R and insulin secretion in response to exogenous GLP-1 in nondiabetic subjects: a pilot study. Diabetes Care. 2010;33(9):2074-6. doi:10.2337/dc10-0200.

11. Dayeh T, Volkov P, Salö S, Hall E, Nilsson E, Olsson $\mathrm{AH}$, et al. Genome-wide DNA methylation analysis of human pancreatic islets from type 2 diabetic and non-diabetic donors identifies candidate genes that influence insulin secretion. PLoS Genet. 2014;10(3):e1004160. doi:10.1371/journal.pgen. 1004160 .

12. Hall E, Dayeh T, Kirkpatrick CL, Wollheim CB, Dekker Nitert M, Ling C. DNA methylation of the glucagon-like peptide 1 receptor (GLP1R) in human pancreatic islets. BMC Med Genet. 2013;14:76. doi:10.1186/1471-2350-14-76.

13. Pan CY, Yang W, Tou C, Gause-Nilsson I, Zhao J. Efficacy and safety of saxagliptin in drug-naïve Asian patients with type 2 diabetes mellitus: a randomized controlled trial. Diabetes Metab Res Rev. 2012;28(3):268-75. doi:10.1002/dmrr.1306.

14. Yang W, Pan CY, Tou C, Zhao J, Gause-Nilsson I. Efficacy and safety ofsaxagliptin added to metformin in Asian people with type 2 diabetes mellitus: a randomized controlled trial. Diabetes Res Clin Pract. 2011;94(2):217-24. doi:10.1016/j. diabres.2011.07.035.

15. Sjöstrand M, Iqbal N, Lu J, Hirshberg B. Saxagliptin improves glycemic control by modulating postprandial glucagon and C-peptide levels in Chinese patients with type 2 diabetes. Diabetes Res Clin Pract. 2014;105(2):185-91. doi:10.1016/j. diabres.2014.05.006.

16. Wang X, Yang J, Chang B, Shan C, Xu Y, Zheng M, et al. Glucagon secretion is increased in patients with Type 2 diabetic nephropathy. J Diabetes Complications. 2016;30(3):488-93. doi:10.1016/j. jdiacomp.

17. Whiting DR, Guariguata L, Weil C, Shaw J. IDF diabetes atlas: global estimates of the prevalence of diabetes for 2011 and 2030. Diabetes Res Clin Pract. 2011;94(3):311-21. doi:10.1016/j.diabres.2011.10. 029.

18. Esposito K, Ceriello A, Giugliano D. Does personalized diabetology overcome clinical uncertainty and therapeutic inertia in type 2 diabetes? Endocrine. 2013;44(1):343-5. doi:10. 1007/s12020-013-0090-0.

19. Li CJ, Liu XJ, Bai L, Yu Q, Zhang QM, Yu P, et al. Efficacy and safety of vildagliptin, Saxagliptin or Sitagliptin as add-on therapy in Chinese patients with type 2 diabetes inadequately controlled with dual combination of traditional oral hypoglycemic agents. Diabetol Metab Syndr. 2014;6:69. doi:10. 1186/1758-5996-6-69. 
20. Sjöstrand M, Iqbal N, Lu J, Hirshberg B. Saxagliptin improves glycemic control by modulating postprandial glucagon and C-peptide levels in Chinese patients with type 2 diabetes. Diabetes Res Clin Pract. 2014;105(2):185-91. doi:10.1016/j. diabres.2014.05.006.

21. Bagger JI, Knop FK, Holst JJ, Vilsbøll T. Glucagon antagonism as a potential therapeutic target in type 2 diabetes. Diabetes Obes Metab. 2011;13(11):965-71. doi:10.1111/j.1463-1326.2011.01427.x.

22. Scheen AJ, Charpentier G, Ostgren CJ, Hellqvist A, Gause-Nilsson I. Efficacy and safety of saxagliptin in combination with metformin compared with sitagliptin in combination with metformin in adult patients with type 2 diabetes mellitus. Diabetes Metab Res Rev. 2010;26(7):540-9. doi:10. 1002/dmrr.1114.

23. Hollander P, Li J, Allen E, Chen R. CV181-013 Investigators. Saxagliptin added to a thiazolidinedione improves glycemic control in patients with type 2 diabetes and inadequate control on thiazolidinedione alone. J Clin Endocrinol Metab. 2009;94(12):4810-9. doi:10. 1210/jc.2009-0550.

24. Göke B, Gallwitz B, Eriksson J, Hellqvist A, Gause-Nilsson I. D1680C00001 Investigators. Saxagliptin is non-inferior to glipizide in patients with type 2 diabetes mellitus inadequately controlled on metformin alone: a 52-week randomised controlled trial. Int J Clin Pract. 2010;64(12):1619-31. doi:10.1111/j.1742-1241. 2010.02510.x.

25. Baron AD, Schaeffer L, Shragg P, Kolterman OG. Role of hyperglucagonemia in maintenance of increased rates of hepatic glucose output in type II diabetics. Diabetes. 1987;36(3):274-83.

26. Shah P, Vella A, Basu A, Basu R, Schwenk WF, Rizza RA. Lack of suppression of glucagon contributes to postprandial hyperglycemia in subjects with type 2 diabetes mellitus. J Clin Endocrinol Metab. 2000;85(11):4053-9.

27. Gromada J, Rorsman P. New insights into the regulation of glucagon secretion by glucagon-like peptide-1. Horm Metab Res. 2004;36(11-12):822-9.

28. Moon JS, Won KC. Pancreatic $\alpha$-Cell Dysfunction in Type 2 Diabetes: old Kids on the Block. Diabetes Metab J. 2015;39(1):1-9. doi:10.4093/dmj.2015.39. 1.1 .
29. Drucker DJ. The biology of incretin hormones. Cell Metab. 2006;3(3):153-65. doi:10.1016/j.cmet.2006. 01.004 .

30. Kushiyama A, Kikuchi T, Tanaka K, Tahara T, Takao $\mathrm{T}$, Onishi Y, et al. Prediction of the effect on antihyperglycaemic action of sitagliptin by plasma active form glucagon-like peptide-1. World. J Diabetes. 2016;7(11):230-8. doi:10.4239/wjd.v7. i11.230.

31. Esposito K, Cozzolino D, Bellastella G, Maiorino MI, Chiodini P, Ceriello A, et al. Dipeptidyl peptidase- 4 inhibitors and $\mathrm{HbA} 1 \mathrm{c}$ target of $<7 \%$ in type 2 diabetes: meta-analysis of randomized controlled trials. Diabetes Obes Metab. 2011;13(7):594-603. doi:10.1111/j.1463-1326.2011.01380.x.

32. Merino B, Alonso-Magdalena P, Lluesma M, Neco P, Gonzalez A, Marroquí L, et al. Pancreatic alpha-cells from female mice undergo morphofunctional changes during compensatory adaptations of the endocrine pancreas to diet-induced obesity. Sci Rep. 2015;5:11622. doi:10.1038/srep11622.

33. Triplitt C, Solis-Herrera C, Cersosimo E, Abdul-Ghani M, Defronzo RA. Empagliflozin and linagliptin combination therapy for treatment of patients with type 2 diabetes mellitus. Expert Opin Pharmacother. 2015;16(18):2819-33. doi:10.1517/ 14656566.2015.1114098.

34. Singh AK, Singh R. Combination therapy of sodium-glucose co-transporter- 2 inhibitors and dipeptidyl peptidase-4 inhibitors in type 2 diabetes: rationale and evidences. Expert Rev Clin Pharmacol. 2016;9(2):229-40. doi: 10.1586/ 17512433.2016 .1123616$.

35. Knop FK, Aaboe K, Vilsbøll T, Vølund A, Holst JJ, Krarup $\mathrm{T}$, et al. Impaired incretin effect and fasting hyperglucagonaemia characterizing type 2 diabetic subjects are early signs of dysmetabolism in obesity. Diabetes Obes Metab. 2012;14(6):500-10. doi:10. 1111/j.1463-1326.2011.01549.x.

36. Otsuka Y, Yamaguchi S, Furukawa A, Kosuda M, Nakazaki M, Ishihara H. Addition of sitagliptin or metformin to insulin monotherapy improves blood glucose control via different effects on insulin and glucagon secretion in hyperglycemic Japanese patients with type 2 diabetes. Endocr J. 2015;62(2):133-43. doi:10.1507/endocrj.EJ14-0148. 